\title{
SISTEM PEMANTAUAN RUANGAN LABORATORIUM DENGAN RASPBERRY PI CAMERA
}

\author{
Donalson Libertin \\ Teknik Elektro,Program StudiTeknik Otomasi Listrik Industri, Politeknik Negeri Jakarta, \\ Jl. Prof.Dr.G.A.Siwabessy, Kampus UI, Depok, 16425 \\ Email: donalsonlibertin@gmail.com
}

\begin{abstract}
In the Electrical Engineering Laboratory 2 nd Floor room, there is a variety of equipment, but the equipment is often lost. So the room needed a monitoring system to see the activity in the room to minimize theft. The purpose of this study is to design a monitoring system using Raspberry Pi Zero $W$ as a link between the Raspberry Pi Camera and the admin. Room conditions can be monitored online and in realtime on the Web. Based on the results of testing video streaming displayed on the Web, there is a delay of 3-4 seconds so that the image moves slower than the actual situation. This device can send a notification of the condition of the room and pictures at 12:00-13:00 when there is movement or someone doing activities in the room. Data is sent via email and google drive @ sctolipnj.
\end{abstract}

Keywords: Raspberry Pi Zero W, Raspberry Pi Camera, Video Streaming, Web, Email, Google Drive.

\begin{abstract}
ABSTRAK
Dalam ruangan Laboratorium Lantai 2 Teknik Listrik terdapat berbagai peralatan praktek namun peralatan tersebut sering hilang. Sehingga pada ruangan tersebut diperlukan sistem pemantauan untuk melihat aktivitas dalam ruangan untuk meminimalisir pencurian. Tujuan penelitian ini adalah merancang sistem pemantauan dengan memanfaatkan Raspberry Pi Zero W sebagai penghubung antara Raspberry P $i$ Camera dengan admin. Kondisi ruangan dapat dipantau secara online dan realtime berbasis Web. Berdasarkan hasil pengujian Video streaming yang ditampilkan pada web, terdapat delay 3-4 detik yang menjadikan video streaming terlambat bergerak dari keadaan sebenarnya, Perangkat ini dapat mengirim pemberitahuan kondisi ruangan dan gambar pada saat jam 12:00-13:00 apabila ada pergerakan atau ada orang yang sedang melakukan aktivitas di ruangan tersebut. Data dikirim melalui email dan google drive @ sctolipnj.
\end{abstract}

Kata Kunci: Raspberry Pi Zero W, Raspberry Pi Camera, Video Streaming, Web, Email, Google Drive.

\section{PENDAHULUAN}

Sistem pemantauan ruangan akan diterapkan pada ruangan Laboratorium Lantai 2 Teknik Listrik Politeknik Negeri Jakarta agar ruangan tersebut terpantau penggunaan ruangnya. Manfaat lain adalah dengan adanya sistem ini maka juga bisa ruangan dapat terpantau untuk menghindari kejahatan seperti pencurian barang oleh orang yang tidak dikenal.
Sistem pemantauan ruangan atau rumah telah banyak dilakukan oleh peneliti, diantaranya adalah pemantauan smart home [1], [2], [3], [6] berbasis raspberi pi. Namun sistem pemantauan pada penilitian tersebut belum ada yang terkoneksi dengan email untuk memberikan notifikasi kepada owner. Notifikasi membantu owner untuk mengetahui kondisi di lapangan.

Sehingga pada penelitian ini, Sistem pemantauan ruangan pada ruangan Laboratorium 


\section{Sistem Pemantauan Ruangan Laboratorium Dengan Raspberry Pi Camera}

Lantai 2 Teknik Listrik Politeknik Negeri Jakarta menggunakan email untuk notifikasi. Hardware yang digunakan adalah Raspberry Pi Camera dan. Raspberry Pi Zero W [4,5]. Raspberry Pi Zero $W$ digunakan sebagai pusat pengendali untuk mengirim notifikasi ke Gmail, serta mengirim gambar dan log data berbentuk excel ke Google Drive ketika Raspberry Pi Camera mendeteksi ada gerakan diruangan tersebut. Untuk melihat atau memonitor keadaan kelas dapat melalui web dengan command http://192.168.43.36/.

\section{METODE PENELITIAN}

\subsection{Flow Chart}

Flowchart berfungsi menjelaskan suatu aliran kerja pada sistem kontrol. Adapun flowchart dari sistem pemantauan ruangan smart class dengan raspberry pi camera ditunjukkan pada Gambar 1.
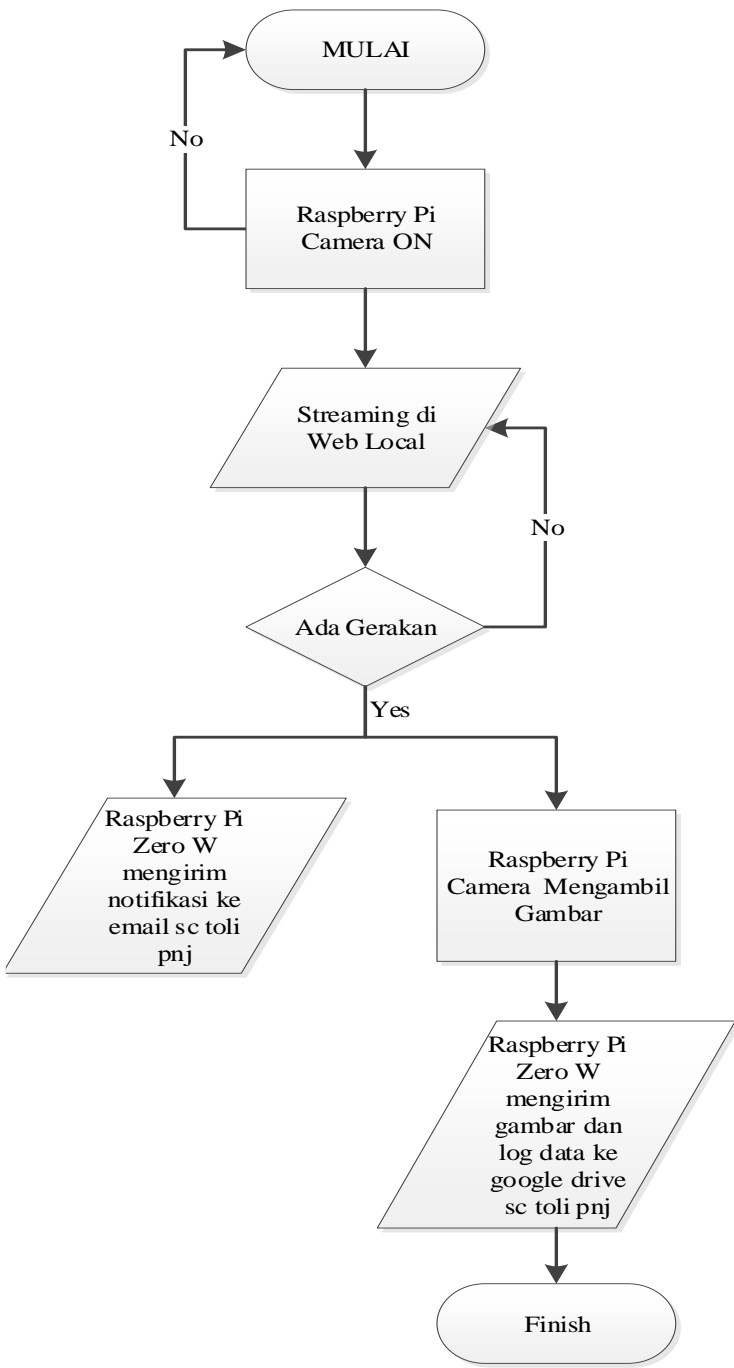

Gambar 1. Flowchart Sistem Pemantauan

ELECTRICES VOL 2 NO 1 APRIL 2020

\subsection{Perancangan Sistem}

Sistem keamanan ini difungsikan secara otomatis pada jam 12.00 - 13.00 WIB. Waktu ini dipilih karena pada waktu tersebut semua mahasiswa dan storemen sedang beristirahat sehingga ruang laboratarium kosong. Sistem ini dimaksudkan untuk merekam gambar atau pergerakan orang yang berada didalam ruangan pada waktu tersebut. Hal ini dilakukan karena banyak kejadian kehilangan peralatan pada waktu tersebut.

Peralatan utama pada sistem pemantauan ini menggunakan Raspberry Pi Zero $W$ sebagai Server utama. Raspberry Pi Camera digunakan untuk merekam semua kejadian yang ada di ruangan. Raspberry Pi Zero $W$ dilengkapi dengan Raspberry Pi Camera yang akan merekam keadaan ruangan apabila terdeteksi gerakan maka Raspberry Pi Zero $W$ akan mengirim sebuah peringatan kepada petugas berupa pesan melalui Email sctolipnj. Kemudian secara bersamaan Raspberry Pi Camera akan merekam video kemudian menyimpannya di memori. Petugas admin dapat melihat secara langsung keadaan ruangan lewat smartphone dan PC yang terkoneksi dengan wifi yang sama melalui web browser. Gambaran umum sistem terlihat pada Gambar 2.

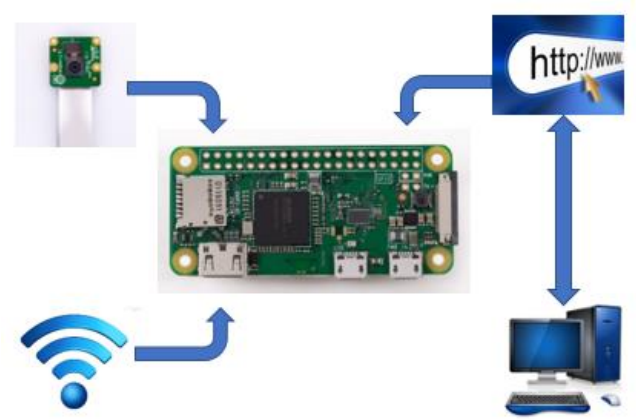

Gambar 2 Gambaran umum Sistem

Berdasarkan peran/fungsi perangkat keras, siste pada Gambar 3, dibagi menjadi 3 bagian yaitu:

a) Sistem Input

Raspberry Pi Camera bertugas memberikan masukan berupa video yang akan disimpan di dalam motioneye dan foto yang akan dikirim ke klien melalui Google Drive sctolipnj atau bisa langsung dikirimkan ke klien secara live streaming.

b) Sistem Pemroses

Raspberry $P i$ sebagai bagian pemrosesan yang utama. Raspberry $P i$ yang digunakan adalah Raspberry Pi Zero W. Raspberry Pi Zero $W$ bekerja pada tegangan $5 \mathrm{~V}$ dan arus maksimal 3A. Raspberry Pi Zero $W$ memerintahkan untuk mengirim notif pesan ke Email dan akan 


\section{Sistem Pemantauan Ruangan Laboratorium Dengan Raspberry Pi Camera}

mengirim gambar dan data log ke Google Drive apabila ada gerakan di ruangan tersebut.

c) Sistem Output

Modem berfungsi untuk menghubungkan Raspberry Pi Zero $W$ ke jaringan internet yang digunakan untuk melihat keadaan ruangan secara live streaming dan mengirimkan pesan pemberitahuan melalui Email sctolipnj.

\section{HASIL dan PEMBAHASAN}

\subsection{Raspberry Pi Zero W}

Input dari Raspberry Pi Camera akan diproses oleh sebuah mini computer yaitu Raspberry Pi Zero $W$ yang memiliki fitur lengkap seperti port micro USB, 40 pin GPIO, dan port micro HDMI seperti terlihat pada Gambar 3. Raspberry Pi Zero $W$ diaktifkan dengan tegangan listrik 5VDC dan arus 2,5 ampere dengan port micro USB yang diperoleh dari Adaptor 5VDC, 2,5A.

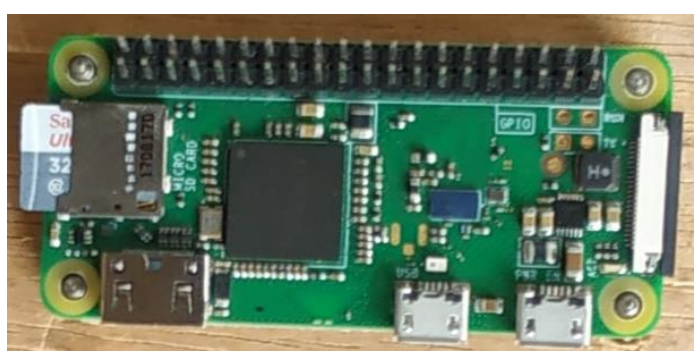

Gambar 3 Raspberry Pi Zero W

\subsection{Web Interface (motioneye)}

Pada penelitian ini, perangkat Raspberry $\mathrm{Pi}$ Camera berfungsi sebagai kamera pemantau dan perekam menggunakan motioneye, sementara Raspberry Pi Zero $W$ berfungsi sebagai server serta kontroler. Secara default Raspberry Pi Camera tidak mampu memberikan informasi apapun terhadap Raspberry Pi Zero W, oleh karena itu harus dilakukan konfigurasi terlebih dahulu. Langkah pertama yaitu menginstal library motioneye, hal ini memungkinkan motioneye dapat berfungsi untuk melakukan pengolahan data gambar maupun video dengan command:

apt-get install python-pip pythondev libssl-dev libcurl4-openssl-dev libjpeg-dev libz-dev

Setelah instalasi library nya selanjutnya unduh paket motioneye dengan command:

pip install motioneye

Di dalam paket motioneye sudah termasuk server tornado, jinja2, pillow, dan pycurl. Langkah selanjutnya yaitu membuat direktori konfigurasi dari motioneye tersebut dengan terlebih dahulu membuat direktori baru dengan command:

mkdir -p /etc/motioneye cp/usr/local/share/motioneye/extra/ motioneye. conf.sample /etc/motioneye/motioneye.conf

Motioneye yang semula berada di direktori /usr/local/share di copy ke direktori letc/motioneye. Setelah membuat direktori konfigurasi selanjutnya membuat direktori baru untuk penyimpanan gambar maupun video dari motion tersebut dengan command:

mkdir -p /var/lib/motioneye

Semua output gambar maupun video hasil rekaman motioneye berada di direktori /var/lib/motion. Supaya motioneye otomatis berjalan ketika booting maka perlu ditambahkan command sebagai berikut:

$\mathrm{cp}$

/usr/local/share/motioneye/extra/mo tioneye.systemd-unit-local

/etc/systemd/system/motioneye.servi ce

systemctl daemon-reload

systemctl enable motioneye

systemctl start motioneye

Setelah membuat direktori baru untuk motioneye service, selanjutnya daemon dijalankan ulang. Daemon memungkinkan supaya motioneye dapat berjalan saat boot. Selanjutnya untuk menjalankan motioneye dengan command servicemotioneyestart.

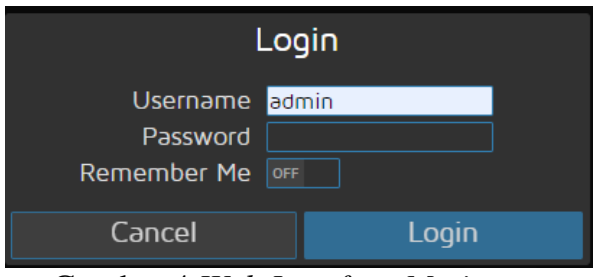

Gambar 4 Web Interface Motioneye

Pada Gambar 4, halaman awal memiliki akses autentifikasi untuk admin maupun klien dalam satu form. Perbedaannya yaitu admin memiliki akses untuk merubah pengaturan seperti resolusi maupun frame rate. Hasil perekaman maupun pemantauan dari raspberri pi camera semua ditampilkan di web dan dapat diakses secara live streaming serta dapat di download. Untuk mendapatkan akses ke web maka harus memasukkan alamat IP Raspberry Pi 


\section{Sistem Pemantauan Ruangan Laboratorium Dengan Raspberry Pi Camera}

Zero $W$ ditambah dengan port 80 (192.168.43.36) melalui browser yang terdapat di device.

\subsection{Konfigurasi}

Pada sistem pemantauan ruangan ini yang berhak melakukan konfigurasi pada halaman web hanya admin. Konfigurasi harus dilakukan pada Google drive dan Gmail. Google drive digunakan untuk menyimpan data video sedangkan email Gmail berfungi untuk memberikan notifikasi kepada admin jika ada orang yang masuk ke dalam ruang lab pada jam 12.00-13.00 WIB tanpa izin admin atau storeman. Konfigurasi gambar ke Google drive dapat dilihat pada Gambar 5.
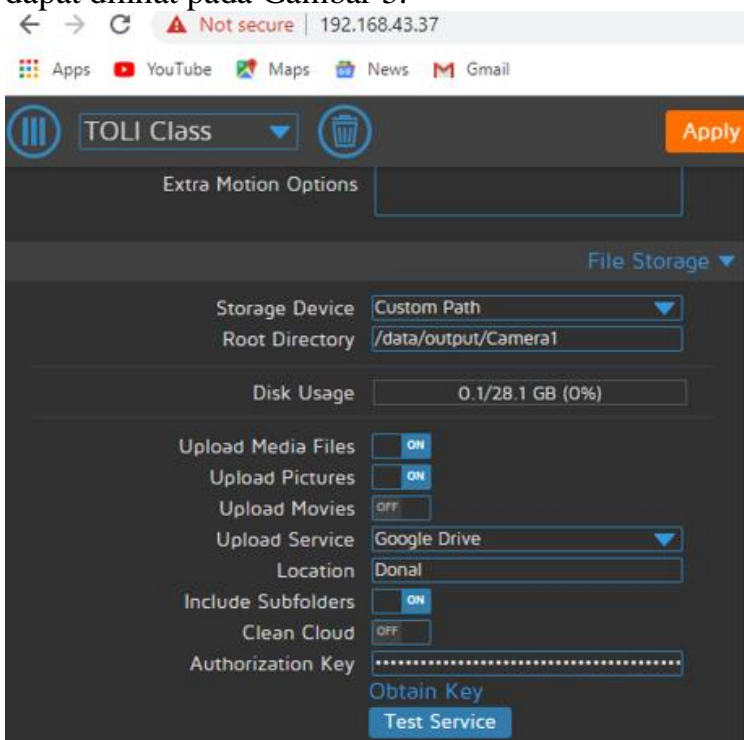

Gambar 5 Konfigurasi Upload Gambar ke Google Drive

Untuk melakukan konfigurasi notifikasi ke Gmail pada sistem pemantauan ini pilih menu Motion Notifikasions, aktifkan menu Send An Email selanjutnya isi kolom yang ada di menu Send An Email seperti dibawah ini:

a) Email Addresses: sctolipnj@gmail.com

b) SMTP Server: smtp.gmail.com

c) SMTP Port : :587

d) SMTP Account: sctolipnj@ gmail.com

e) SMTP Password: "password"

f) From Address: sctolipnj@gmail.com

Setelah mengisi kolom menu Send An Email, aktifkan menu Use TLS > Test Email. Selanjutnya memilih menu Apply di atas bagian tengah sistem pemantauan. Dapat dilihat pada Gambar 6.

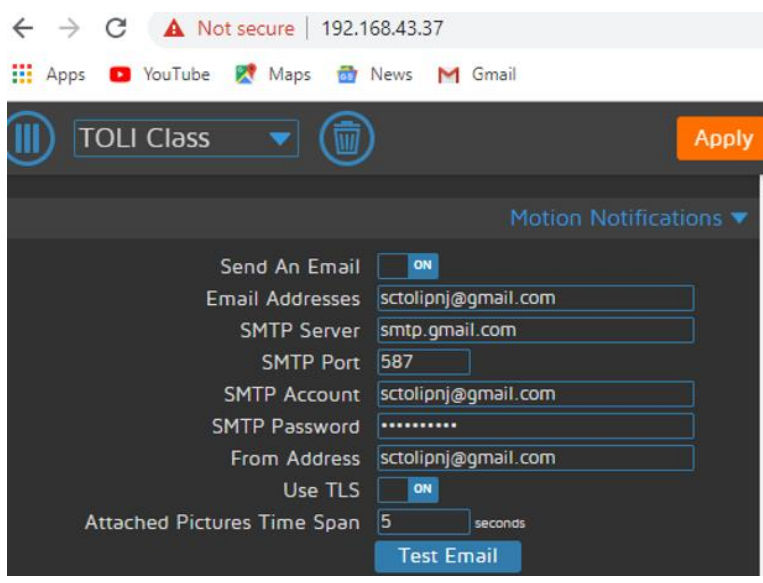

Gambar 6 Konfigurasi Notifikasi ke Gmail

Sistem pemantauan ruangan lab dilakukan berdasarkan dua kondisi, yaitu sesuai jadwal yang telah ditentukan dan di luar jadwal yang telah ditentukan. Kondisi sesuai jadwal yang telah ditentukan yaitu pada hari senin sampai jumat jam 12:00-13:00 sistem pemantauan ini akan bekerja dengan merekam keadaan ruangan tersebut. Apabila raspberry pi camera mendetaksi ada gerakan di ruangan smart class ini, raspberry pi zero $w$ akan mengirim notifikasi ke Email sctolipnj, mengirim gambar dan data log ke Google Drive sctolipnj.

Untuk melakukan konfigurasi jadwal kerja pada sistem pemantauan ini pilih menu Working Schedule, aktifkan Working Schedule selanjutnya isi kolom yang ada di menu Working Schedule seperti dibawah ini:

a) Monday : From 12:00 to 13:00

b) Tuesday : From 12:00 to 13:00

c) Wednesday : From 12:00 to 13:00

d) Thursday : From 12:00 to 13:00

e) Friday : From 12:00 to 13:00

f) Detect Motion: During Working Schedule

Selanjutnya pilih menu Apply di atas bagian tengah sistem pemantauan. Dapat dilihat pada Gambar 7.

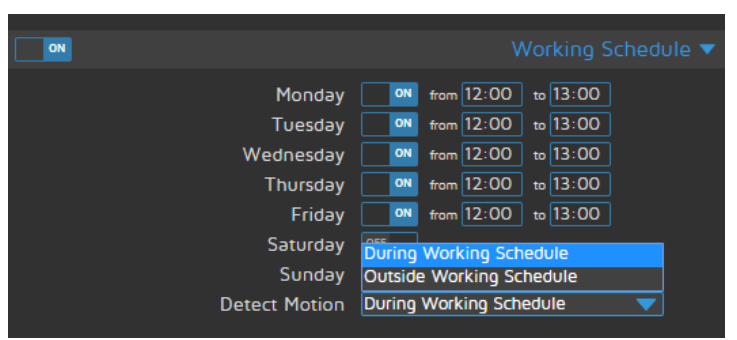

Gambar 7 Konfigurasi Jadwal Kerja Sistem Pemantauan

\subsection{Pengujian Pengiriman Notifikasi ke Gmail \\ Pengujian pengiriman notifikasi Gmail ini bertujuan untuk mengetahui waktu pengiriman}




\section{Sistem Pemantauan Ruangan Laboratorium Dengan Raspberry Pi Camera}

pemberitahuan melalui Gmail sctolipnj ketika raspberry pi camera mendetaksi ada gerakan diruangan tersebut.

Metode pengukuran pengiriman pada pengujian ini menggunakan stopwatch pengukuran. Hasilnya terdapat delay pengiriman notifikasi ke Gmail seperti pada Tabel 1.

Tabel 1 Hasil Pengujian Pengiriman Notifikasi Gmail

\begin{tabular}{ccccc}
\hline No & Objek & $\begin{array}{c}\text { Objek } \\
\text { Terdeteksi }\end{array}$ & $\begin{array}{c}\text { Delay } \\
\text { Notifikasi } \\
\text { Gmail } \\
\text { (detik) }\end{array}$ & Keterangan \\
\hline 1 & Manusia & Terdeteksi & 3 & Masuk \\
2 & Manusia & Terdeteksi & 4 & Masuk \\
3 & Manusia & Terdeteksi & 3 & Masuk \\
4 & Manusia & Terdeteksi & 3 & Masuk \\
5 & Manusia & Terdeteksi & 4 & Masuk \\
\hline
\end{tabular}

Delay terjadi karena koneksi internet dari provider. Jika kecepatan koneksi tinggi maka delay minimal. Namun delay 3-4 detik masih dalam batas toleransi. Dengan delay ini storeman atau admin dapat langsung menuju lokasi.

\subsection{Pengujian Pengiriman Gambar dan Data Log ke Google drive}

Pengujian pengiriman gambar dan data log ini bertujuan untuk mengetahui waktu pengiriman gambar dan data log melalui Google Drive sctolipnj ketika raspberry pi camera mendetaksi ada gerakan diruangan tersebut.

Metode pengukuran pengiriman pada pengujian ini menggunakan stopwatch pengukuran. Hasil pengujian pengiriman gambar dan data log melalui Google Drive. Dapat dilihat pada Gambar 8 dan 9.

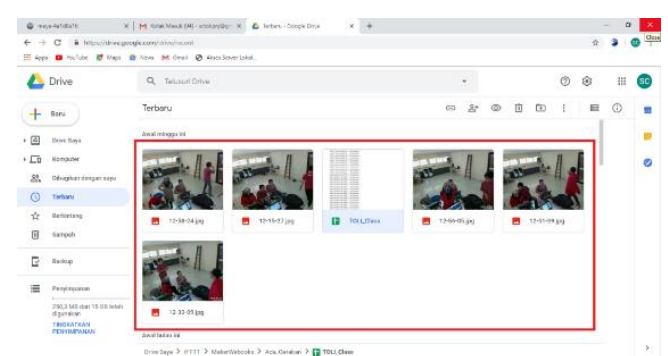

Gambar 8 Hasil Pengujian Pengiriman Gambar

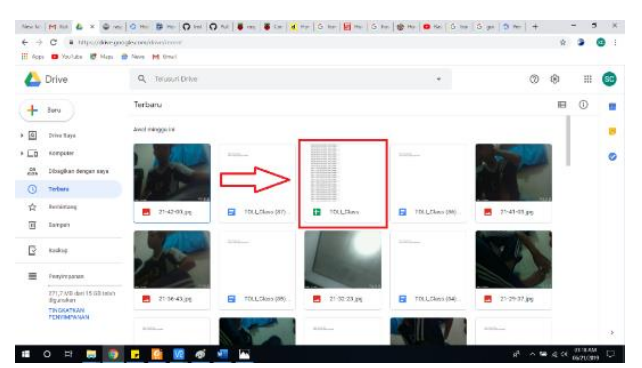

Gambar 9 Hasil Pengujian Data Log
Berdasarkan hasil pengujian pengiriman data gambar dan data log ke Google Drive sctolipnj, gambar dan data dapat secara otomatis masuk ke google drive. Namun pada proses ini juga terdapat delay sebesar 3-4 detik. Faktor penyebabnya adalah kecepatan internet yang menjadi faktor utama terhadap kecepatan pengiriman gambar dan data log tersebut.

\section{KESIMPULAN}

Sistem pemantauan ruangan Laboratorium Lantai 2 Teknik Listrik telah berfungsi dengan baik sesuai kondisi yang telah ditetapkan. Pergerakan orang dapat terdeteksi dan proses tersebut terekam dengan baik walaupun terjadi delay. Pengiriman notifikasi ke admin melalui email terjadi delay sekitar 3-4 detik. Sedangkan pengimiman data gambar ke Google drive juga terjadi delay yang sama.

\section{DAFTAR PUSTAKA}

[1] Dwiyaniti, M., Atmaja, I. T., Firdaus, Y., \& Noveansyah, H. (2019). Pengembangan Multiplatform Pengendali Dan Pemonitor Perangkat Listrik Pada Miniatur Smart Home. ELECTRICES, 1(1), 1-8.

[2] Gerung, R. A., Fadilah, K., Wardani, Y., Dwiyaniti, M., \& Mulyadi, W. H. (2019). Aplikasi Asisten Virtual Sebagai Perintah Suara Pada Sistem Otomatisasi Rumah Tinggal. ELECTRICES, 1(1), 9-14.

[3] D. E. Kurniawan and S. Fani, "Perancangan Sistem Kamera Pengawas Berbasis Perangkat Bergerak Menggunakan Raspberry Pi," J. Ilm. Teknol. Inf. Terap., vol. III, no. 2, pp. 140-146, 2017.

[4] R. Pi Zero, "Nick Heath," 2012. [Online]. Available:

https://www.techrepublic.com/article/raspb erry-pi-zero-wireless-the-smart-personsguide/. [Accessed: 15-Jun-2019].

[5] C. Crisan, "Raspberry Pi Camera," 2017. [Online].

Available: https://www.raspberrypispy.co.uk/2017/04/raspberry-pi-cctvcamera-with-motioneyeos/. [Accessed: 10Jun-2019].

[[6] M. I. KURNIAWAN, U. SUNARYA, and R. TULLOH, "Internet of Things: Sistem Keamanan Rumah berbasis Raspberry Pi dan Telegram Messenger," ELKOMIKA J. Tek. Energi Elektr. Tek. Telekomun. Tek. Elektron., vol. 6, no. 1, p. 4, 2018.

[7] Fathroni, E. Prayetno, and T. Suhendra, "Sistem Pemantau Realtime Pada Ruang 
Server Kantor Badan Pengelola Pajak Dan Retribusi Daerah Kabupaten Bintan," pp. 1-12, 2017.

[8] P. Studi, T. Informatika, M. Wakhid, and N. Hidayat, "Analisis Perbandingan Broadcast Tv Streaming Pada Jaringan Lan Dan Wireless-Lan," 2012.

[9] Martinez, "Pengertian dan Cara Kerja IFTTT (If This Then That)," pp. 12-13, 2011. 